fishery suddenly doubled, and since then the catch has gone on increasing until now the fishery produces 75,000 dozen erabs more than it did before the law was changed, an increase worth 185,000 dollars to the fishermon (N. B. Scofield in California Fish and Game, 1932, p. 260). Yet originally they opposed the change, saying that already at six inches the size limit was too high, and that declining production could be stayed only by permitting the capture of smaller individuals through the reduction of the sixinch limit. Once more, scientifically ascertained facts have triumphed over opinion and so-called experience.

\section{W. E. Dixon Memorials}

Two mernorials to the life and work of the late Prof. W. E. Dixon, who was reader in pharmacology in the University of Cambridge until his sudden death on August 16, 1931 (see Nature, 128, 401, Sept. 5, 1931) are being established. The first, already in being, is due to the action of the British Medical Association, which has named one of its most valuable research scholarships the "W. E. Dixon Memorial Scholarship". The second is to take the form of a lectureship. Certain of Dr. Dixon's friends, under the ehairmanship of Sir William Willcox, opened in 1931 a fund for this purpose. The final meeting of subscribers to this fund was held at the house of the Royal Society of Medicine on June 1. This meeting resolved that the money collected $(£ 700)$ should be used to establish a "W. E. Dixon Memorial Lecture" which should be delivered biennially or triennially, on some subject of pharmacological or therapeutic interest. The Royal Society of Medicine was invited to undertake the trusteeship of the fund. The response to the appeal which was issued has been extraordinarily wide. Present and past students, colleagues, former colleagues, and personal friends in Great Britain, the United States, and on the Continent, have all contributed. In addition, donations have been sent from representatives of commercial firms, and from several learned societies, both at home and abroad. This response shows how wide was Dixon's influence, and how warmly his qualities were appreciated.

\section{Composition of the Stars}

ON June 1 the annual Halley lecture at the University of Oxford was delivered by Prof. Henry Norris Russell, professor of astronomy and director of the University Observatory, Princeton, on the subject of the "Composition of the Stars". $\mathrm{He}$ remarked that the statement of Comte about a century ago, that no human being could ever learn anything of the composition of the stars, was speedily invalidated by the detection of various elements in the sun by the employment of spectrum analysis. From the adaptation by Huggins of suitable spectroscopis, it was soon ascertained that the same substances as occurred in the sun were also to be found in the stars. It was next made clear that the stars fell into natural classes, white, yellow and red, with intergrades. The stellar conditions of extreme heat made it possible to investigate the properties of matter at their simplest. The intensities of the lines of the spectrum were almost as important as their position. Iron was shown to be abundant in the sun, copper next, silver comparatively rare. Fifty-eight elements are now known in the sun; improvements in apparatus will no doubt disclose others. Sir Norman Lockyer was right in surmising that atoms themselves are structural, they disintegrate in white stars; he was again right in holding that the width of a line is proportional to the number of atoms producing it. In the interior of stars, the atoms of light elements are disintegrated by the collision of protons with the nuclei. There is an unsearchable part of the solar spectrum; the lines of the missing elements may occur within it. At the conclusion of the lecture, diagrams were shown which gave the number of atoms actually concerned in different kinds of stars.

\section{Artificial Transmutation of the Elements}

ON June 2 at Oxford, under the auspices of the Junior Scientific Club, the annual Boyle lecture was delivered by Lord Rutherford, who took as his subject the "Artificial Transmutation of the Elements". He described the pioneer achievement of Messrs. Cockeroft and Walton at the Cavendish Laboratory in applying the high-voltage method of generating fast streams of protons for producing atomic transformation, and detailed recent developments of method by which it was possible to obtain still greater results at a lower voltage. Further modifications had led to conclusions of high interest, and the new type of projectile now in use will no doubt result in extending the knowledge of types of possible transformation. It was probable that further assaults would be made on the stability of the nucleus, and there was already evidence of the appearance of a positively charged particle of mass comparable with that of the negative electron.

\section{Constitution and Temperament in Man}

IN Scientia, 53, 4, K. H. R. Edwards outlines the chief lines of approach to the study of the relationship between constitution and temperament, namely, the genetic, the teleological, the physiological, and the psychopathological. He realises that such differentiations are of descriptive rather than practical utility. He discusses the data relevant to the problem as presented by Bartlett, McDougall, Kretschmer, Pavlov, and Jaensch, and, perhaps somewhat optimistically, concludes that in the near future the advances in physiology, psychiatry and psychology will solve the problem. Discussions on temperament are complicated by the vagueness of writers as to the meaning of the word, coupled with the fact that popularly it is used for emotional instability, so that a well-balanced person would not be accredited with any temperament. The concept arose out of the observation that individuals differ in susceptibility to disease, and the hypothesis that this was due to some difference in physiological make-up (crasis, temperamentum, complexion) is at least as old as Hippocrates, although generally known 